\title{
Crash Repair in the UK: Reusing Salvaged Parts in Car Repair Centres
}

\begin{abstract}
The reuse of salvaged parts from vehicles, deemed to be at the end of their life, is viewed as an opportunity by insurers and crash repair firms to reduce rectification costs and improve service to policy holders. This research investigates the opportunities and challenges that confront an important but under researched part of the automotive supply chain in establishing a reverse logistics flow of salvaged parts. The aim of this article is to explore why the development of a reverse logistics system for the reuse of salvaged parts has not been successful in the UK yet flourishes in North America and Europe. Through answering this question the paper seeks to provide a framework for managing the development of a partial closed-loop reverse logistics system for salvaged parts. Economic and ecological benefits are identified as potential outcomes. The implications for practice and further research are discussed.
\end{abstract}

Keywords: closed-loop, reuse; salvage; crash repair sector; reverse logistics

\section{Introduction}

Increased legislation and concerns with the environmental impact of waste has developed a drive by organisations to reduce, repair and recycle product at the end of their life. Companies are recognising that used products can represent a valuable resource in servicing customers and meeting legislative requirements (Fleischmann et al, 2003). Realising the value-add inherent in used products requires the establishment and operation of a reverse logistics system (Knemeyer et al, 2002). Simple explanations of reverse logistics suggest that the logistical flow follows the original flow from producer to user but in reverse order (Zikmund and Stanton 1971). Most supply chains however have been designed for unidirectional flow with consideration for a structure that could support reverse logistics or redistribution of used parts being overlooked (Bernon and Cullen 2007).

The reverse flow of salvaged parts to be reused in the repair of cars is a common occurrence in North America. Several large distributions firms have evolved to manage the recovery and reuse of salvaged parts from end-of-life vehicles (ELV's), salvage parts for reuse being defined as components that can be reused without any need for change (Tang and Naim 2004). In Europe, the EU has issued a statement encouraging reuse of salvaged parts for the repair of cars (European Commission, 2009). There are several countries in Europe including Germany and the Netherlands which actively use salvaged parts in the repair of cars. The UK is facing similar pressure to other European countries in terms of growing regulation and landfill reduction targets. However its crash repair sector has been unable to establish a reverse logistics network to reuse salvaged parts.

The purpose of this paper is to explore the reasons why the UK crash repair sector struggles to establish a reverse logistics system whilst other European and North American countries routinely reuse salvaged parts. Initially the paper compares and contrasts the differences between countries reusing salvaged parts in terms of 
market and governance structures to provide an insight into their impact on decision making and subsequent reuse of parts. The paper then reviews the current literature on reverse logistics and the reuse of salvaged parts comparing, contrasting and augmenting it with the analysis of findings from the research project. This review is followed by a discussion of a potential framework for the establishment of a partial closed-loop reverse logistics system. The paper concludes with suggestions for future research.

\section{Market Structures in the Crash Repair Sector}

The crash repair sector in the UK has different market characteristics compared to other EU and North American countries. Within the UK insurance market companies operate a risk reduction and customer retention strategy for car repairs. When a vehicle is involved in an accident the insurer will strive to repair the car at a nominated supplier. The nominated accident repair centre operates to an agreed industry standard using approved equipment and repair methods as specified in PAS125 Kitemark (British Standards Institute, 2007). No other country has evolved an accredited accident repair standard that stipulates how a crashed car can be returned to a roadworthy condition. The standard also specifies what tools, materials and methods should be used to execute the transaction by industry assessed and trained technicians. To achieve accreditation, repair centres have had to invest in equipment and people to improve their capability to support the PAS125 Kitemark standard. Operating with an industry standard reduces the risk of poor vehicle repair for the insurer and policy holder. The exchange between the insurer and the crash repair centre is one of interdependency and aligns with a relational governance structure.

In other EU countries insurers reduce their risk by issuing the policy holder with a cheque allowing the customer to action their own repair therefore shifting responsibility to the car owner. This approach minimizes insurer risk as repair centres in these markets operate independently (unless they are dealerships which were outside the scope of this study) without any recognized standards of repair to codify and support the transaction. EU insurers take a market governance approach to managing the repair process. Parts to be used in the repair are decided by the policy holder. Repairing the vehicle, as opposed to presenting the policy holder with a cheque, is the modus operandi of UK insurers and supports the continued relationship with the customer. Issuing of a cheque does not guarantee the customer will purchase a replacement car or continue to insure with the original insurance firm. The majority of car ownership in the UK is by individuals who are exposed to price comparison website marketing. Payment of a cheque leads, in general, to a lost customer for the insurer.

In North America over $60 \%$ of cars are owned by lease companies who focus on minimizing lost time off the road for clients. Insurance is predominately paid through lease charges therefore the insurance company-crash repair centre relationship is different from the EU. Time and cost is the focus for lease companies and insurers. Crash repair centres are driven for quick turnaround and lowest cost under a market governance structure. Reused parts are viewed as a lower cost option for lease firms when repairing cars. Car repairs in North America use more than $40 \%$ of parts reclaimed from ELV's. 
The various market and governance structures used in Western countries are shown in Table 1. The discussion on the impact of the unique UK governance and market structure on the forward flow of parts and the development of the reverse logistics system will be elaborated in the findings section of the paper.

Table 1 Comparison of Crash Repair Sector Markets

\begin{tabular}{|l|l|l|l|}
\hline Region & $\begin{array}{l}\text { Predominant Car } \\
\text { Ownership Model in } \\
\text { Market }\end{array}$ & $\begin{array}{l}\text { Governance Structure } \\
\text { Insurer-Repair Centre }\end{array}$ & $\begin{array}{l}\text { Parts Use Decision } \\
\text { Maker }\end{array}$ \\
\hline UK & Private & Relational & $\begin{array}{l}\text { Insurer through } \\
\text { PAS125 }\end{array}$ \\
\hline EU (excluding UK) & Private & Market & Policy Holder \\
\hline North America & Lease & Market & Leasing Firm \\
\hline
\end{tabular}

\section{Reverse logistics and the reuse of salvaged parts}

Authorised treatment facilities have been in existence for many years and some larger facilities have recently become regulated salvage agents for the dismantling of ELV's in the UK. With the increase of ELV legislation several dismantler firms have upgraded their capabilities by investing in equipment and staff in order to attain a license to operate. Historically dismantler firms had been characterized by limited capital investment and poor technical qualifications with the quality of work performed not graded to any industry standards (Renato et al, 2002). The licensed salvage companies are responsible for reporting to BERR (Department for Business Enterprise and Regulatory Reform) on recovering metals from shredding activities, oils and fluids, tyres, batteries, recycling of non-metallic materials and non-metallic spare parts sold. The reverse logistic flow of salvaged parts, in this traditional reverse logistics system, is informal with few controls in terms of quality, quantity and timing. Lambert and Stock (1981) defined reverse logistics as "going the wrong way on a one-way street because the great majority of product shipments flow in one direction". The crash repair sector has historically had a "one-way" approach to ELV's and their component parts. Once the car is deemed to have attained ELV status the next stage in the supply chain is the dismantler (to remove the oils, tyres and mechanical items for remanufacturing) followed by crushing and shipment to landfill. The ELV supply chain was designed for unidirectional flow.

Limited evidence exists of manufacturers moving cars back from the vehicle owner to the plant in Europe for salvage operations (Gerrard and Kandlikar 2007). Currently the forward distribution networks of vehicle manufacturers do not engage with the reverse logistics operation of the supply chain for reused parts to create a closed-loop. Fleischmann et al (2003) define closed-loop systems as being an "ensemble of interrelated inbound and outbound flows". The operation of a closedloop system could be of major interest to vehicle manufacturer parts suppliers as crash repair centres spare parts sales are a significant part of their profits (Seitz and Peattie 2004). Fleischmann et al (1997) noted that reuse often leads to closed-loop systems where the parts are returned to the original producer. Evidence in automotive sector research would appear to question if parts are being reused and consequently questions the development of a closed-loop system for the sector. Kumar and Yamaoka (2007) researched the Toyota reverse logistics system and found that 80- 
$83 \%$ by weight of the car is recycled. Doors, bonnets and door panels are recycled back to metals but, not reused as parts for repairs or spares. This contrasts with the desire of insurance firms to use these major car components in the UK reverse logistics system.

Fleischmann et al (1997) when investigating reverse distribution networks identified key aspects that should be considered when planning the establishment of an efficient and effective reverse logistics operation. Two of these aspects relate to the identification of the actors in the reverse distribution network and the relationship between the forward and reverse supply chain. Actors in the UK crash repair supply chain includes policy holders (vehicle owners), insurers, crash repair centres, salvage agents, logistics providers, dismantlers, shredders, Original Equipment (OE) parts suppliers and specialist service providers. The actors within this supply chain do not exist in isolation but have to interact with external influences. External regulating and competitive factors can impact on the establishment of reverse logistics (Carter and Ellram 1998). Within the crash repair sector regulation exists in the form of industry standards, government and European legislation. Competitive factors include demands from buyers who purchase recycled materials such as metal and plastics and alternative parts suppliers.

The quality requirement of parts, to be reused, depends upon the process that will be employed (Thierry et al 1995). It is important that the quality requirements have to be supported by the reverse logistics operation that provides redistribution of reused product. Quality was identified by Ravi and Shankar (2005) as an important issue in establishing a reverse flow of parts in the Indian automobile industry, as well as a lack of efficient information systems, resistance to change for reverse logistics activities, reluctance of dealers, distributors and retailers to become involved.

Knemeyer et al (2002) researched the factors which affected the reverse logistics of end- of- life computers (ELC) separating the external and internal dimensions. External dimensions included the factors highlighted by Carter and Ellram (1998) as well as the input sources of ELC and the output stage of the reverse logistics operation in terms of purchases of recycled materials and refurbished computers. Internally they identified three stages including the operational factors of inbound processing (separation of items for recycling or reuse), value-add (repair of ELC's) and outbound processing (recycling or refurbishment). The Knemeyer et al (2002) model provides a useful framework for researching reverse logistics. However within the crash repair sector there are additional factors that need to be considered including; the acceptability of reused parts in the repair process to policy holders, the role of salvage agents/brokers in deciding the fate of the ELV and the alternative, competing, supply of parts to the crash repair centre from existing spare parts manufacturers. The methodology employed in the research is explained in the next section.

\section{Research Method}

The evolving nature of the phenomenon led the researchers to initially employ an explorative research strategy involving interviews and focus groups. Initial interviews were held with interested crash repair supply chain sector participants to discuss potential research topics and known issues (Golicic et al 2003). These initial interview questions were general in nature and were used to illicit early concerns and opportunities that a reverse logistics operation could bring forth. The outputs from the initial phase of research were used to develop an interview protocol and semi- 
structured questions (Knemeyer et al 2002). The authors utilised the approach recommended by Eisenhardt (1989) that before entering the field to conduct qualitative research researchers ought to specify constructs a-priori. The initial interviews and the information derived from the literature review on the establishment of a reverse logistics operation were used to derive a-priori constructs and a tentative framework. It was important to interview a broad range of stakeholders to ensure that participants represented a wide perspective on the evolving phenomenon. Participants in interviews were selected from the same supply chain and potential reverse logistics operation to counter respondent bias (Heide and Miner 1992). Two separate reuse crash repair sector supply chains were investigated representing two different insurance companies. Stakeholders included policy holders, insurers, vehicle manufacturers, crash repair centres, salvage agents, dismantlers and industry standards organisations. Interviews lasted between 60 and 90 minutes and were held, when possible, at the interviewees property. Conducting the interviews at the participants property also provided the opportunity to directly observe the firm's environment and collect any documented evidence. Interviews were recorded, transcribed and thematically coded.

Focus groups were held with members representing insurers, crash repair centres, industry standards, salvage brokers and dismantlers. The groups were assembled by the researchers to discuss the challenges and opportunities facing the industry in establishing a reuse supply chain. Feed back to focus group was achieved through a presentation of findings to the group and/or on an individual basis. This approach also allowed the opportunity for participants to confirm or challenge the findings. Other meetings were organized by industry groups to discuss the way forward for the reuse of salvaged parts in the repair process. The researchers attended these meetings to capture the discussions and obtain any supporting documentation that was produced. Through attendance at the industry group meetings the researcher can affect the subject being investigated. In order to try and negate this effect, the researchers attended the meetings as observers only.

The evidence collected from the focus and industry groups was triangulated with the interviews to compare, contrast and augment the literature review and develop the tentative framework (Figure 1). The tentative framework depicts the current unidimensional flow and actors involved in an ELV as it progresses through the crash repair sector supply chain (Bernon and Cullen 2007, Fleischmann et al 1997). The model includes the external and internal factors that affect the vehicle movement through the crash repair supply chain. The external dimensions relate to regulation on recycling, reuse, repair and the competitive element of alternative buyers from the output of the process and alternative parts supplier (Carter and Ellram 1998). Internally the model begins with the input of the policy holder crashing the vehicle, moving onto the value-add stage of the crash repair centre assessing the damage and repairing the car if economically viable before, moving onto value-add capture operations including the dismantler (after the vehicle is given ELV status) and finally on to the process outputs stage including landfill (Guide 2000, Knemeyer et al 2002). The tentative framework was used as a starting point to explore the development of a reverse logistics operation for crash repairs. Several key findings were derived from this evidence and are discussed in the next section.

Figure 1. Current ELV supply chain 


\section{Findings}

The analysis of data collected from interviews with potential stakeholders of the reverse logistics operation revealed several key findings. These findings have been grouped into external components of the potential reuse operation in terms of competitive and legislative forces and internal elements related to inputs, value-add and value-capture operational and process outputs.

\subsection{External elements}




\section{Competitive forces}

The operation of a closed-loop system could be of major interest to vehicle manufacturers (Seitz and Peattie 2004). Pricing levels at parity or close to OE part supply may encourage vehicle manufacturers to enter the market, control the flow of salvaged parts and close the loop in the supply chain. OE parts and copy parts suppliers could also offer another type of competition in the form of price reduction to compete with reused parts therefore nullifying some of the price benefit of salvaged parts. Insurers and crash repair centres would welcome either of these two options as this would ensure the integrity of the part and the process. However there has been no movement from the vehicle manufacturers towards either option.

Alternatively high prices may encourage other actors to enter the market and establish an alternative open reverse logistics operation. Interviewees suggested that the higher the price achieved for the salvaged part the greater the likelihood of external actors entering the market to establish alternative open supply chains. "I would expect a non-OE parts supplier to enter the market and distribute salvaged parts if prices of salvaged parts increase or their availability improves" stated an insurer. Another competing force is the buyers for recycled metals, plastics and glass. The establishment of a reverse logistics operation will reduce the volume of materials available to firms from recycling ELV's. This could push prices up for recycled materials and undermine the margins made from the reuse of salvaged parts rendering a reverse logistics operation commercially unattractive.

\section{Legislative forces}

The ELV (Producer Responsibility) Regulations 2005 requires vehicle manufacturers to manage their products from cradle to grave. Legislation stipulates an $85 \%$ reuse, recycling and recovery rate for all vehicles being treated by dismantlers. The dismantlers are responsible for reporting to BERR (Department for Business Enterprise and Regulatory Reform) on recovering metals from shredding activities, oils and fluids, tyres, batteries, energy from smelting, recycling of non-metallic materials and non-metallic spare parts sold. The legislation allows for the reuse of recovered parts. However, the use of these items is very limited in the crash repair process. Future targets for reuse, recycling and recovery from ELV's is expected to reduce the volume allowed to be disposed of through landfill putting increased pressure on producers to improve their performance. "Vehicle manufacturers will have to stop producing spare parts and instead use the services of firms like ours" stated one dismantler. Instead of the supplying replacement parts for crash repairs the manufacturers could support the development of a closedloop reverse logistics operation. Crash repair firms interviewed expected that the external pressures to reduce repair costs by insurers (via salvaged parts) and the impact of legislation on landfill will drive vehicle manufacturers to participate in the development of a reverse logistics system to support reuse.

\subsection{Internal elements}

Process inputs (policy holder-insurer) 
The initial input into the ELV supply chain is the occurrence of an accident involving a policy holder and the resultant actions of the insurer. This dyadic relationship operates on an understanding that the insurer where contractually bound, will take appropriate action to repair the crashed car in accordance with the policy and under the rules of subrogation. Subrogation provides the insurer with the authority to act on behalf of the private car owner. Insurers through the power of subrogation have the potential to deploy reused parts in the repair process but may choose not to. Insurers have a non-contractual policy of indemnity therefore do not need consent of the policy holder to use salvaged parts. Several issues were identified from interviews with insurers on the use of salvaged parts. Gaining policy holders' acceptance that salvaged parts can be used in the repair of their vehicle is a challenge and an opportunity. Policy holders have a dualistic perspective on the use of salvaged parts. Ecologically they support the concept however they do not want "second hand" parts on their own vehicle.

Insurers differ on the approach that should be taken to involve the policy holder in the decision of which parts (in terms of source) should be used in the repair. Some insurers plan to alter their contracts to allow accredited salvaged parts to be used once the policy holder gives consent. This authorised use of salvaged parts is also being supported by trialling price reduction incentives. Others view this as an unnecessary action and will take the option that suits the situation in terms of providing best value for the policy holder therefore removing this obstacle to progress. The decision to use salvaged parts lies with the insurer through subrogation. This varied response may hinder and ultimately lead to the failure of the reverse logistics operation if policy holders become sceptical about the insurers intentions. Policy holder power through switching contracts could halt the development of a reverse logistics system for reused parts. Customer retention is "paramount to the success of the scheme", as one insurer stated.

Insurance firms have a dual focus on using salvaged parts, in terms of their economic and ecological benefits. The insurance industry has a growing concern to develop and improve its corporate social responsibilities and views the reuse of salvaged parts as one way in which they can support the environment. The insurers plan the development of a marketing awareness campaign for the promotion of reused parts as an ecological benefit.

\section{Value-add operations}


Interviews were conducted with twelve crash repair centre firms to understand the issues and challenges faced by them using salvaged parts. The three most recurring themes from the firms were the quality, safety and availability of parts. Quality of salvaged parts in terms of their condition and fit for purpose was a regular issue. "If I need a blue door for a car and the salvage company send me a red one who pays for the rework?" is highlighted as an example of one issue. The repairer in this example will have to remove the paint, reprime and re-paint as a policy holder may notice the colour difference in the event of future scratches. The crash repair centres had several concerns about the cost of any non-conformity work related to salvaged parts. The insurers and dismantlers are challenging this potential obstacle by stating that any additional costs would be borne by the salvaged parts supplier through price reduction or replacement.

Safety related parts were highlighted by all members of the supply chain. No clear definition exists of what type of part would be included in the reuse scheme. The Motor Insurance Repair Research Centre at Thatcham in the UK is currently researching this area to assess which items should be included or excluded from a safety perspective. For example air bags are reused in North America but all firms within the UK chain, except the salvage brokers, rejected their use. The risk adverse nature of the UK insurance industry will also exclude the reuse of any parts deemed to be safety critical including pedestrian contact parts (e.g. bumpers), mechanical and hydraulic parts.

Within the last two years the crash repair sector including insurers has embraced a voluntary repair specification through the implementation of PAS125 (BSI 2007). The scheme stipulates the use of OE parts in the repair process. Ethically the insurers would be undermining their own scheme if they mandated salvaged parts to be used in the process by crash repair centres. Overcoming this obstacle will require the establishment of standards for the process of dismantling, grading of salvaged parts and an agreement on types of parts that can be reused. Through the establishment of an industry parts grading and accreditation process (like PAS125) for the dismantling process and the parts they supply the crash repair firms expected that potential quality problems would be minor. "If they set-up a specification similar to PAS then we shouldn't really have any problems" was the view of one crash repair centre owner. The relational governance approach of insurers with nominated repairers also means that the introduction of reused salvaged parts has to be negotiated instead of imposed.

Standard OE parts supply is a major problem for crash repair centres as it directly impacts on their profitability. The cycle time of repairs is known as "key to key" time by repairers and represents the time from the car key arriving on site to it being returned to the policy holder. "Our key to key time is severely impacted by parts availability" stated one manager. The impact of delays can lead to an increase in cycle time of 4-7 days and increased costs due to double handling, rework, lost labour productivity and further vehicle damage.

Integrating the supply of salvaged parts with a poorly performing OE parts supply is viewed as an opportunity to improve service by repair centres. From a crash repair centre perspective the level of inventory held, speed of delivery and ease of use of parts will determine the success of any reverse logistics operation in terms of economic and customer service benefits. Supply of salvaged parts from ELV's depends on the number and frequency of vehicles involved in crashes. Forecasting 
availability and consumption could be a major obstacle in establishing a reverse logistics operation as information on number of repairs, type of repair and frequency is not held centrally by any business or institution. Integrating confidential information from different commercial enterprises will be needed to derive the volume and number of salvaged parts to be stored across the UK. The development of a reverse logistics system will have to be supported by the industries estimator system providers working together to provide a common information platform.

\section{Value-added capture operations}

The value-added capture operation is centred on the functions of the dismantler and the logistical operation that supports the movement, storage and distribution of salvaged parts. The raison d'etre for dismantlers currently is the dismantling of the ELV to recover as much value from the vehicle in terms of recycling. Recovering parts for reuse is an opportunistic, localised activity due to the limited market opportunity open to them. Establishing a reverse logistics operation requires the simultaneous opening of the car insurance market to dismantlers if it is to be viable and effective. For the operation to be effective the process has to be able "to recognise when a car should be dismantled for parts or shredded" stated one salvage agent. "We don't want to send the vehicle for dismantling for parts if they are not needed" he stated. If there is sufficient inventory in the system to meet (insurers) forecasted demand the ELV may be sent directly to recycling rather than be dismantled. Inventory imbalances can lead to added costs of excessive inventory in the reverse logistics operation.

Dismantlers use a multitude of bespoke systems and spreadsheets to record parts numbers, inventory levels and sales. Currently a dismantler's main route to market is through retail over the counter sales or on the internet via spare parts web sites. Insurers use industry standard estimating systems with their crash repair centres to evaluate the quantity, type and age requirement of parts. The challenge for the reverse logistics operation is to link the two systems so crash repair centres can order parts online. Currently spreadsheets and emails are being trialled to link supply and demand. The insurer checks stock availability with the dismantler through an emailed spreadsheet and then notifies the repairer that stock is available. The dismantler checks the crash repair centres order and faxes back confirmation. This process can take hours or even days. This process will continue to be a major obstacle to the success of reusing salvaged parts until an online ordering system, linked to the industry estimating software, is developed.

The volume of inventories planned and the type to be held by dissemblers in the UK is currently based on experience with no formal stock replenishment systems. The information made available by the ELV supply chain stakeholders limits the opportunity for the disassembler to plan and manage inventory. Linking the crash repair management estimating system to the dismantlers data base is one option being considered. "If a UK wide salvaged part network is to become a reality, accessing this data will require sharing of proprietary information held by different industry system providers" stated a salvage agent. The variety of parts that can be recovered from ELVs in terms of different manufacturers models, number of components in a vehicle and issues with regards to assessing the quality of the part returned means that the task facing the disassembling operator is complex. This level of complexity impacts on the knowledge required by the operators, disassembling tools required and the costs recovered. The actors in the reverse logistics operation will be faced with 
recovery (labour and overheads) and control of these costs. The costs connected with the logistics operation could be significant and along with disassembly will have to be apportioned across the supply chain. "We need a standard list of parts to begin with to be able to establish a delivered cost model" stated one insurer.

Standardising the dismantling and parts approval process will also support the development of an information technology (IT) solution that can track the movement, visibility and inventory control of parts in the supply chain. The crash repair sector has an "IT infrastructure that can be easily adapted to support the reverse logistics system", stated one insurer. Improved supply through the use of salvaged parts could enable improved service to policy holders; reduce waste in the current repair process, lower cycle times and increase profit were the expected benefits envisaged by several insurers, salvage agents and dismantlers. An issue inherent in any system that is developed will be the challenge of the same component part having different OEM codes. Within North America reused parts distributors have developed software which supports them in identifying common parts therefore reducing duplication of inventory and improve availability.

Standardisation of the process is not limited to computer systems. The industry is also planning to establish a PAS125 equivalent standard for vehicle dismantling. The new standard will codify the processes, tools, training requirements, quality checks and storage conditions for salvaged parts. The new specification will support the salvage firms in establishing competencies related to their processes and define industry standard equipment and checks. The operation of recovering parts will still require capable suppliers using tacit knowledge as well as codified processes.

One of the principal areas of contention in the establishment of the reverse logistics system relates to the price mechanism that will govern the exchange, movement and ownership of salvaged parts. Pricing needs to recover costs of labour to recover the part, the inherent value captured in the item and logistics expenses. Added to the costs are the margins required by the supply chain members to deliver a profitable operation. Contention exists between the insurers about the "best approach" to pricing. A cost plus or OE part price equivalent is the debate that is ensuing. "Pricing and price agreements by insurers will drive the pace of establishing an operation that supports the use of salvaged parts", stated one salvage agent. The commercial sensitivity around pricing policy is a potential inhibitor to the establishment of a reverse logistics system as well as an attractor to competition.

\section{Process outputs}

Through the reuse of salvaged parts the companies interviewed envisaged little or no changes to the outputs of the ELV disposal, recycling or remanufacturing processes, other than a reduction in the volume of landfill. The current modus operandi would be unchanged in the context of this review

\subsection{Discussion and analysis}

Reverse logistics systems practice and research has evolved over the years into an expanding body of literature providing solutions for organizations in how to overcome some of the inherent obstacles of reversing the flow of parts and materials (Guide and Van Wassenhove, 2003). Literature on reverse logistics is dominated by research into closed-loop systems involving the original manufacturer (Bernon and 
Cullen, 2007, Ravi and Shankar, 2005). Vehicle manufacturers have the opportunity to engage with the crash repair sector to reduce landfill by reusing parts however, they are faced with a conflict between profit preservation from the sales of original spare parts supply and the need to reduce landfill. When and if they enter the market for salvaged parts a closed-loop system is expected to be developed. Closed-loop structures allow the manufacturer to exploit returns as a source of spare parts, route to extend product life and are a contributor to improved service (Fleischmann et al 2003, Banomyong et al, 2008).

Currently the crash repair sector has detected no interest from vehicle manufacturers for reusing salvaged parts and is therefore progressing with the development of a partially closed-loop system consisting of a combination of an open reverse logistics and a partially closed-loop system. The proposed partially closedloop system will consist of both an open ELV supply chain that recycles, remanufactures and disposes (via landfill) of waste and partially closed with respect to the reverse flow from the dismantler to crash repair centre but not back to the vehicle producer. The closed-loop section of the crash repair sector supply chain faces several obstacles to overcome before it becomes operational. Each of the major obstacles and potential resolutions are as follows:

Insurers and Policy Holder Resistance: The greater the support of the policy holder for the use of salvaged parts in the crash repair process the more insurers can support and grow the market for salvaged parts. Insurers are attempting to reduce resistance through economic and ecological incentives. Incentivising policy holders with price reductions if reused salvaged parts are authorised is an approach that insurers are trialling to assess the price-sensitivity of customers to the concept. Cost driven perspective is the dominant approach in the EU and North America. UK insurers are also planning the development of a marketing awareness campaign for the promotion of reused parts as an ecological benefit that the policy holder can support. Increasing the awareness of the benefits, economically and environmentally, should lower resistance (Ravi and Shankar 2005). Insurers have a third option, due to subrogation, as they can use salvaged parts without consultation. This option is viewed as high risk due the potential loss of the policy holder's custom.

Insurers and Crash Repair Centres Concerns: Cost, availability and quality are concerns which dominate discussions between repairers on the use of salvaged parts. Pricing of salvaged parts entering the reverse logistics system is an issue that sector has yet to address. Salvaged parts prices in the UK will be reduced by salvage agents if remedial work is required, to offset any costs incurred to make a part fit for purpose. The smaller the price difference between salvaged and OE prices the greater the level of competition for the reverse logistics operation and the increased profitability challenge. Competitive pricing is essential to the success of all reverse logistics operations in the car crash repair sector. Price however is not the only motivator for using salvaged parts as total cost is important to insurers and repairers. If availability of parts can be increased the cost issues of repair process delays can be reduced. Insurers view salvaged parts use by repair centres as essential in improving customer service and retention and therefore may mandate their use.

Salvage Agent/Dismantler Capability: The introduction of an accredited approval system to ensure quality and safety testing for salvaged parts is viewed by insurers as a key tool to reduce/remove this resistance by the repair centres. Thierry et al (1995) highlighted that the quality of reused parts must be at the quality of the virgin product a sentiment echoed by the crash repair centres. For reused parts to align with the needs of the crash repair sector an industry standard will have to be 
developed for UK value-added capture capabilities in terms of the process for dismantling and grading of parts. North American salvage agents quality inspect and provide warranties as part of their service offering to increase car crash repair centre confidence.

Information System Support: Information systems support is another area that is significant in establishing a reverse flow for salvaged parts. Ravi and Shankar (2005) reported there was a dearth of good information systems to support reverse logistics. Without information system support the firms involved have difficulty managing inventories and also understanding the associated costs of the activities. The UK is developing its information systems, based on current estimating and crash repair management systems, to support inventory reporting however, cost allocation will be a matter of negotiation. Within North America salvaged parts distributors have developed a platform and product coding software which support the identification, storage, sales and distribution of parts.

The greater the transparency of information held on historical repairs the more responsive the reverse logistics system can be through the availability of inventory. Information on demand for crash repair parts in terms of type, volume and frequency is not held centrally in the UK. Salvaged parts inventories are largely independent of demand for spare parts due to the lack of visibility in the supply chain. Information is held across several insurers and estimating data bases each owned by competing firms. For traditional closed-loop systems, operated by a manufacturer, accessing this information still does not provide a complete answer to the question of how many to hold and where (Fleischmann et al 2003). For a partially closed-loop system this issue becomes even more critical in supporting inventory management.

OEM and Alternative Parts Supply Competition: For the partially closed-loop model, of the crash repair sector, the system is open to competing and broadening deliveries of new parts from OEM's, alternative parts suppliers as well as the salvaged parts it delivers. For the reverse logistics system to succeed the quality, delivery and price that is provided has to meet or exceed the performance of the OEM or alternative parts suppliers. The significant margins that vehicle manufacturers and alternative parts suppliers make from spare parts sales may lead to their eventual involvement in the reverse logistics operation. Insurers anticipate that the development of a salvage parts supply system will lead to margin erosion for OEM parts as the vehicle manufacturers respond to reducing volumes. Another option open to the manufactures is to close the loop and govern the flow of salvage parts reuse themselves.

\section{Summary Analysis}

The summary of the analysis on barriers and potential enablers faced by organisations trying to establish a reverse logistics system is shown in Table 2. The table highlights some common issues and potential solutions found in the UK, EU and North America (NA) when organisations plan to develop reverse logistics systems for the reuse of salvaged parts in car crash repairs.

Insurers and other reverse logistics system stakeholders are identifying opportunities to remove the barriers that currently exist. Educating customers on the economic and ecological benefits of salvaged parts is a theme that is being developed by Europe wide insurance companies. North America offers possible answers on parts quality assurance issues and system infrastructure challenges. Reduced cycle time through increased parts availability can lower costs and provide a competitive 
advantage for developing reverse logistics systems when faced with the challenges of OEM's.

Table 2 Reverse Logistics Barriers and Enablers

\begin{tabular}{|c|c|c|}
\hline Reverse Logistics Elements & Barrier & Enabler \\
\hline Customer support & $\begin{array}{l}\begin{array}{l}\text { Policy holder expects } \\
\text { replacement part to be new } \\
\text { (UK) }\end{array} \\
\text { - } \begin{array}{l}\text { Insurance policy supports } \\
\text { use of only new parts (UK) }\end{array}\end{array}$ & $\begin{array}{ll}\text { - } & \begin{array}{l}\text { Customer education on } \\
\text { ecological and economic } \\
\text { benefits (UK \& EU) }\end{array} \\
\text { - } & \text { Price reductions incentives } \\
\text { on repair costs linked to } \\
\text { policy changes (UK) } \\
\text { Cost and service driven } \\
\text { decisions by customers } \\
\text { (EU \& NA) }\end{array}$ \\
\hline Crash repair centre support & $\begin{array}{l}\text { Increased costs due to } \\
\text { remedial work to make fit } \\
\text { for purpose salvaged parts } \\
\text { (UK) }\end{array}$ & $\begin{array}{ll}\text { - } & \text { Competitively priced parts } \\
\text { (UK, EU \& NA) } \\
\text { - } & \text { Parts priced to offset } \\
& \text { additional costs to repair } \\
\text { centre(UK) } \\
\text { - } \\
\text { Insurer mandate (UK) } \\
\text { Increase parts availability } \\
\text { (UK, EU \& NA) } \\
\end{array}$ \\
\hline $\begin{array}{l}\text { Salvage agent/dismantler } \\
\text { capability }\end{array}$ & $\begin{array}{l}\text { Higher potential of } \\
\text { reduced quality salvaged } \\
\text { parts compared with new } \\
\text { OEM components (UK, } \\
\text { EU \& NA) }\end{array}$ & $\begin{array}{ll}- & \text { Accredited salvage } \\
\text { recovery system (UK) } \\
\text { Warranty on quality } \\
\text { inspected parts (NA) }\end{array}$ \\
\hline Information system structure & $\begin{array}{l}\text { Non-aligned information } \\
\text { system between insurer } \\
\text { and salvage agent (UK ) }\end{array}$ & $\begin{array}{l}\text { - Common platform and } \\
\text { product coding software } \\
\text { (NA) }\end{array}$ \\
\hline OEM parts competition & 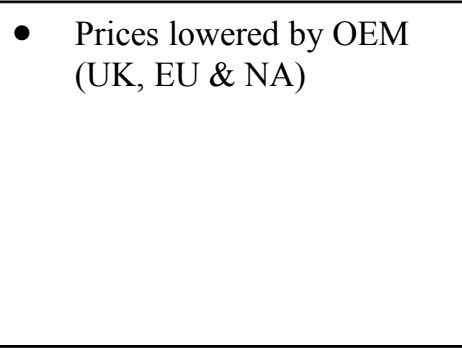 & $\begin{array}{ll}\text { Increase product } \\
\text { availability for repairers } \\
\text { from expanded parts } \\
\text { supply (UK, EU \& NA) } \\
\text { Reduced costs of repair } \\
\text { and improved customer } \\
\text { service due to cycle time } \\
\text { reduction (UK, EU \& NA) }\end{array}$ \\
\hline
\end{tabular}




\subsection{Conclusion}

Determining and understanding the obstacles and opportunities that face the crash repair sector in establishing a reverse logistics operation for salvaged parts is, we believe, original research in a poorly investigated link in the automotive sector. The researchers have developed a tentative framework for structuring a reverse logistics operation that utilises a partially closed-loop system. Research has shown that there is an opportunity for crash repair centres to use salvaged parts to improve cycle time, reduce costs and improve customer service however several barriers will have to be removed before the concept can become reality. The identified barriers have begun to answer the research question posed at the outset of this study - why has the UK crash repair sector not been able to develop a reverse logistics operation? Removing these barriers through the application of some of the identified enablers will support the sector in establishing an economically and ecologically important reverse logistics operation.

\subsection{Future Research}

Many studies have investigated the structures and issues faced by firms in establishing a reverse logistics system for product returns either in terms of complete product or salvaged parts within the context of a closed-loop supply chain. This study has investigated the reverse logistics system from the perspective of both an open and closed-loop reverse logistics system. The coordination challenges and the technical problems faced by the system highlight the issues that need to be addressed and researched if independent firms (from the producer) are to deliver ecological and economic benefit from end-of-life products. Modelling the reverse logistics system of the dismantling process to calculate the inventory required to service the demand of the crash repair centres and deliver profitable improvement in the supply chain is an area that further research is required. Exploring the coordination and governance structures of a partially closed-loop system is another area that requires further study. Finally investigating methods for incentivising policy holders to engage with the process of using salvaged parts is a challenging field for research as without the participation of the consumer the system can not operate.

\section{References}

ABP., Insurers worried about their supply chains. Available online at: http://www.abpclub.co.uk/abp-members-forum.htm (accessed 24 April, 2009) Banomyong, R., Veerakachen, V. and Suptan, N., Implementing leagility in reverse logistics channels, International Journal of Logistics: Research and Applications, 2008, 11(1), 31-47

Bernon, M. and Cullen, J., An integrated approach to managing reverse logistics", International Journal of Logistics: Research and Applications, 2007, 10(1), 41-56 British Standards Institute, PAS 125:2007: Automotive services. Vehicle body repair. Specification, 2007 (London: BSI) 
Carter, C. and Ellram, L.M., Reverse logistics: a review of literature and framework for future investigation, Journal of Business Logistics, 1998, 19(1), 85-102

Department for Business Enterprise and Regulatory Reform 2005, Guidance on the End of Life Vehicle Regulations (on line). Available from:

http://www.berr.gov.uk/whatwedo/sectors/sustainability/elv/page30591.html (accessed 10 February, 2009)

European Commission 2009, "Report on the implementation of Directive 2000/53/EC on End-Of-Life Vehicles for the period 2005-2008" (on line). Available from: http://ec.europa.eu/environment/waste/elv_index.htm (accessed 2 March, 2010) Eisenhardt, K.M., Building Theories from Case Study Research, Academy of Management Review, 1989, 14(4), 532-550

Fleischmann, M., van Nunen, J. A.E.E. and Grave, B. Integrating closed-loop supply chains and spare-parts management at IBM, Interfaces, 2003, 33(6), 44-56

Fleischmann, M., Bloemhof-Ruwaard, J.M., Dekker, R., van der Laan, E., van Nunen, J.A.E.E., Van Wassenhove, L.N., Quantitative models for reverse logistics: a review, European Journal of Operational Research, 1997, 103, 1-17

Gerrard, J. and Kandlikar, M., Is European end-of-life vehicle legislation living up to expectations? Assessing the impact of the ELV Directive on 'green' innovation and vehicle recovery, Journal of Cleaner Production, 2007, 5(1), 17-27

Golicic, S.L., Foggin, J.H. and Mentzer, J.T., Relationship magnitude and its role in interorganizational relationship structure, Journal of Business Logistics, 2003, 24(1), $57-75$

Guide Jr., V.D.R., Production planning and control for remanufacturing: industry practice and research needs, Journal of Operations Management, 2000, 18, 467-483 Guide, V. and Van Wassenhove, LN. Business aspects of closed-loop supply chains, In Guide VR, Van Wassenhove, LN editors, Business aspects of closed-loop supply chains: exploring the issues, Pittsburgh, Pens., Carnegie Bosch Institute,2003, pp 1742

Heide, J. and Miner, A., The shadow of the future: effects of anticipated interaction and frequency of contact on buyer-supplier cooperation, Academy of Management Journal, 1992, 24(2), 265-291.

Hoek, van R., The purchasing and control of supplementary third-party logistics services, The Journal of Supply Chain Management, 2000, Fall, pp14-26

Knemeyer, A.M., Ponzurick, T.G. and Logar, C.M., A qualitative examination of factors affecting reverse logistics system for end-of-life computers, International Journal of Physical Distribution and Logistics Management, 2002, 32(6), 455-479 Kumar, S. and Yamaoka, T., Systems dynamics study of the Japanese automotive industry close-loop supply chain, Journal of Management Technology Management, 2007, 18 (2), 115-138

Lambert, D.M. and Stock, J.R., Strategic Physical Distribution Management, 1981, (London:Irwin)

Ravi, V. and Shankar, R., Analysis of interactions among the barriers of reverse logistics, Technological Forecasting and Social Change, 2005, 72, 1011-1029 Renato, O., Hond, den F. and Clegg, S., The political economy of automobile recycling in Eyrope, Organization Studies, 2002,Vol. 23, (40), pp 639-665 Seitz, M.A. and Peattie, K., Meeting the Closed-Loop Challenge, California Management Review, 2004, 46(2), 74-89

Seitz, M.A., A critical assessment of motives for product recovery: the case of engine remanufacturing, Journal of Cleaner Production, 2007, 12, 1147-1157 
Tang, O. and Naim, M.M., The impact of information transparency on the dynamic behaviour of a relational manufacturing/remanufacturing system, International Journal of Production Research, 2004, 42(19), 4135-4152

Thierry, M., Salomon, M., van Nunen, J.A.E.E., Van Wassenhove, L.N., Strategic issues in product recovery management, California Management Review, 1995, 37 (2), 114-135

Zikmund, W. and Stanton, W., Recycling solid wastes: A channels-of-distribution problem", Journal of Marketing, 1971, 35 (3), 34-39 